\author{
Report No. BMI-1453 \\ UC-25 Metallurgy and Ceramics \\ (TID-4500, 15th Ed.)
}

Contract No. W-7405-eng-92

\title{
APPARATUS FOR THE STUDY OF FISSION-GAS RELEASE FROM FUELS DURING POSTIRRADIATION HEATING AT TEMPERATURES UP TO $1600 \mathrm{C}$
}

by

Russell H. Barnes

Duane N. Sunderman

July 22, 1960

BATTELLE MEMORIAL INSTITUTE

$505 \mathrm{King}$ Avenue

Columbus 1, Ohio 


\section{DISCLAIMER}

This report was prepared as an account of work sponsored by an agency of the United States Government. Neither the United States Government nor any agency Thereof, nor any of their employees, makes any warranty, express or implied, or assumes any legal liability or responsibility for the accuracy, completeness, or usefulness of any information, apparatus, product, or process disclosed, or represents that its use would not infringe privately owned rights. Reference herein to any specific commercial product, process, or service by trade name, trademark, manufacturer, or otherwise does not necessarily constitute or imply its endorsement, recommendation, or favoring by the United States Government or any agency thereof. The views and opinions of authors expressed herein do not necessarily state or reflect those of the United States Government or any agency thereof. 


\section{DISCLAIMER}

Portions of this document may be illegible in electronic image products. Images are produced from the best available original document. 
TABLE OF CONTENTS

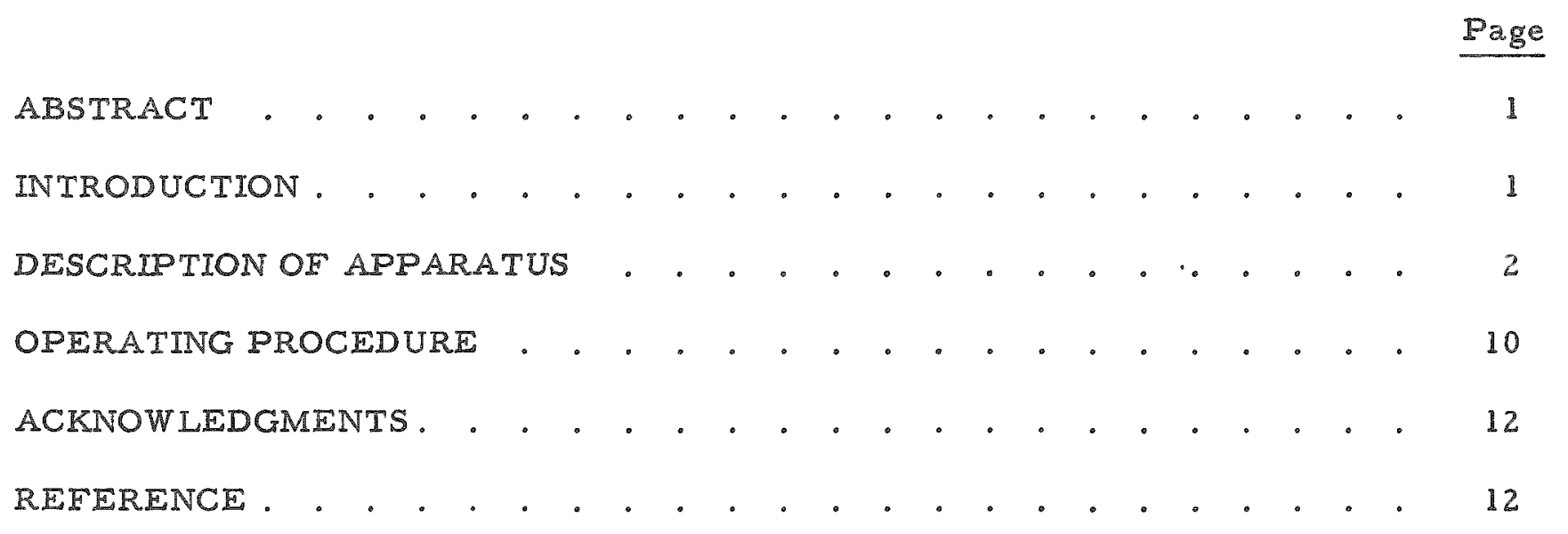




\title{
APPARATUS FOR THE STUDY OF FISSION-GAS RELEASE \\ FROM FUELS DURING POSTIRRADLATION HLAILING AT TEMPERATURES UP TO $1600 \mathrm{C}$
}

\author{
Russell H. Barnes and Duane N. Sunderman
}

\begin{abstract}
An apparatus to study rare-gas fission-product release from nuclear fuel materials during postirradiation heating was developed. Xenon and lrypton fission gases escaping from a small specimen during heating at constant temperature are measured using a continuous radioactivity monitor and charcoal adsorption traps. The rhodiumwound furnace is capable of operation at $1600 \mathrm{C}$. Helium carrier gas is purified by activated alumina, copper, and zirconium traps, and the oxygen and moisture contents of the gas are monitored coninuously. The operating procedure and data are presented for a typical heating experiment in which fused uranium dioxide was studied. Data analysis is in progress and will be presented in subsequent reports.
\end{abstract}

\section{INTRODUCTION}

Knowledge of the ability of ceramic fuel materials to retain gaseous fission products is important for efficient use of the se materials in nuclear reactors. A program is currently in progress at Battelle to investigate fission-gas release from ceramic fuel materials during heating following thermal-neutron irradiation and during reactor irradiation. This report describes the apparatus used for the study of krypton and xenon release from the se materials during postirradiation heating at temperatures up to $1600 \mathrm{C}$.

A previous report described a much simpler apparatus developed specifically for the measurement of fission-gas release from neutron-activated fueled graphite(1). In the work with graphite materials, the gas-release experiment was used primarily for the screening of fueled specimens prior to in-pile evaluation in capsule or loop experiments. For this reason a precise control of environmental factors during heating, such as carrier-gas purity and flow rate and temperature, was not required. In the apparatus described here, precise control of the se factors was necessary since minor variations could affect significantly the magnitude of the diffusion coefficients to be measured.

During heating of an irradiated specimen, a flowing stream of helium transports the evolved fission gas through a continuous radioactivity monitor and then to charcoal adsorption traps where the fission gas is removed from the helium for quantitative analysis. Expeximents with this apparatus are conducted to gain insight into the release mechanism and to determine rare-gas diffusion coefficients as a function of temperature.

A description of the in-pile system and the experimental results associated with this program will be presented in later reports.

(1) References at end. 


\section{DESCRIPTION OF APPARATUS}

The general details of the apparatus for studying xenon and krypton release from uranium-bearing ceramics are shown schematically in Figure 1. A small specimen is irradiated to produce a sufficient quantity of a suitable gamma-emitting isotope which can be used to follow the evolution of xenon and krypton from the specimen. Convenient isotopes for this purpose are 10.3-year krypton-85, 2.8-hr krypton-88, 9. 1-hr xenon135, and 5.3-day xenon-133. The irradiated specimen is heated at a constant temperature inside a vacuumtight ceramic tube which passes through a rhodium-wound resistance furnace. Helium is used as a carrier gas to continuously convey the fission-product rare gases to the point of radioassay. The radioassay is performed in a counting chamber where the gamma activity associated with a single gamma-ray photopeak is meas ured with $a$ 2 by $2-i n$. scintillation crystal of thallium-activated sodium iodide in conjunction with a single-channel spectrometer. The xenon and krypton are then collected from the helium for quantitative analysis in a series of activated-charcoal adsorption traps which are changed at frequent intervals during an experiment. The data from the charcoal traps are used to calibrate the continuous monitor, so that the release rate of a particular isotope can be determined as a function of heating time.

Photographs of the apparatus are presented in Figures 2 and 3. The apparatus is assembled in three separate units. The helium-purification system, and the electrical controls and instruments which are assembled as two separate, portable units, are 10cated outside a California-type hood. The remainder of the system is located inside the hood. The portion of the gas system external to the hood is completely metal, while primarily glass construction is used in the hood. The glass system is prepared in sections which are connected by ball-and-socket joints. This permits disassembly of the system for cleaning and replacement of components.

Helium is supplied to the system from gas cylinders. The helium is first passed through the purification system which removes moisture, oxygen, and nitrogen. The purification system consists of a Lectrodryer, a copper gettering trap, and a zirconium gettering trap. Moisture is removed by the Lectrodryer, which is essentially a packed column of activated alumina through which the gas passes. The Lectrodryer is provided with a heater so that the activated alumina can be regenerated periodically. The copper trap operates at a temperature of about $400 \mathrm{C}$ and the zirconium at $800 \mathrm{C}$. The oxygen and moisture contents of the purified helium are continuously measured by purging a portion of the gas through a Beckman Model 80 oxygen trace analyzer and a Beckman electrolytic hygrometer. The trace analyzer requires a helium flow rate of 6 liters per hr and the hygrometer about 3 liters per hr. Both instruments can measure concentrations of less than $1 \mathrm{ppm}$. This gas-purification system is capable of reducing oxygen and moisture concentrations to the range from 1 to $5 \mathrm{ppm}$.

After the purification section, the carrier gas flows through a throttling valve and then a Cartesian manostat to maintain a constant carrier-gas flow rate in the system. The puxpose of the throttling valve is to permit the purification section to operate at a pressure of about 5 psig and the rest of the system to operate under slight vacuum. A. mechanical vacuum pump on the downstream end of the system is used to transport the helium carrier gas through the system. The desired helium flow rate is attained by adjusting the Cartesian manostat and a throttling valve located at the inlet to the mechanical pump. For experiments, gas flow rates from 1 to 100 liters per hr at pressures ranging from 100 to $500 \mathrm{~mm}$ of mercury are conveniently available. 


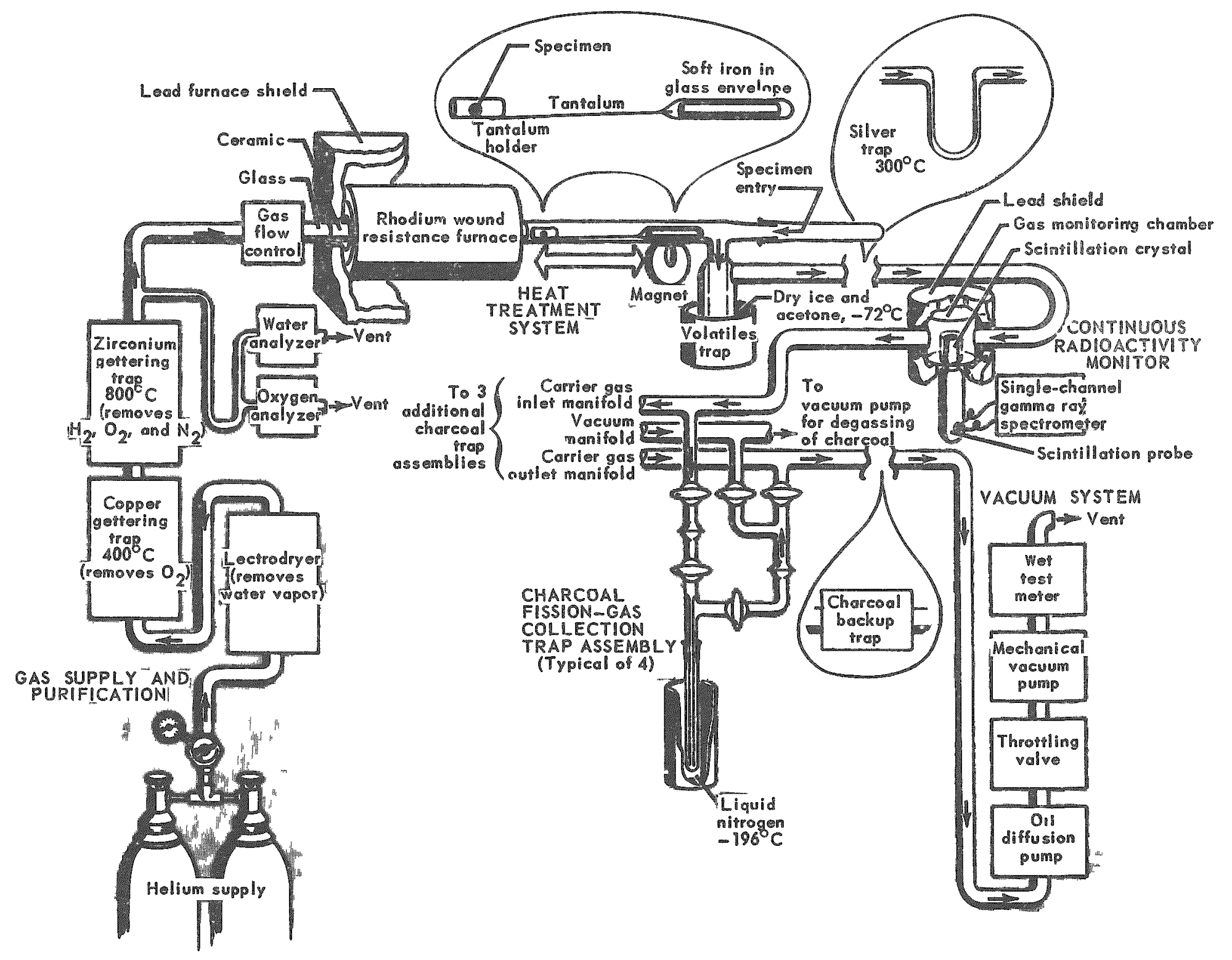

FIGURE I. SCHEMATIC OF APPARATUS FOR POSTIRRADIATION FISSION-GAS-RELEASE STUDIES 

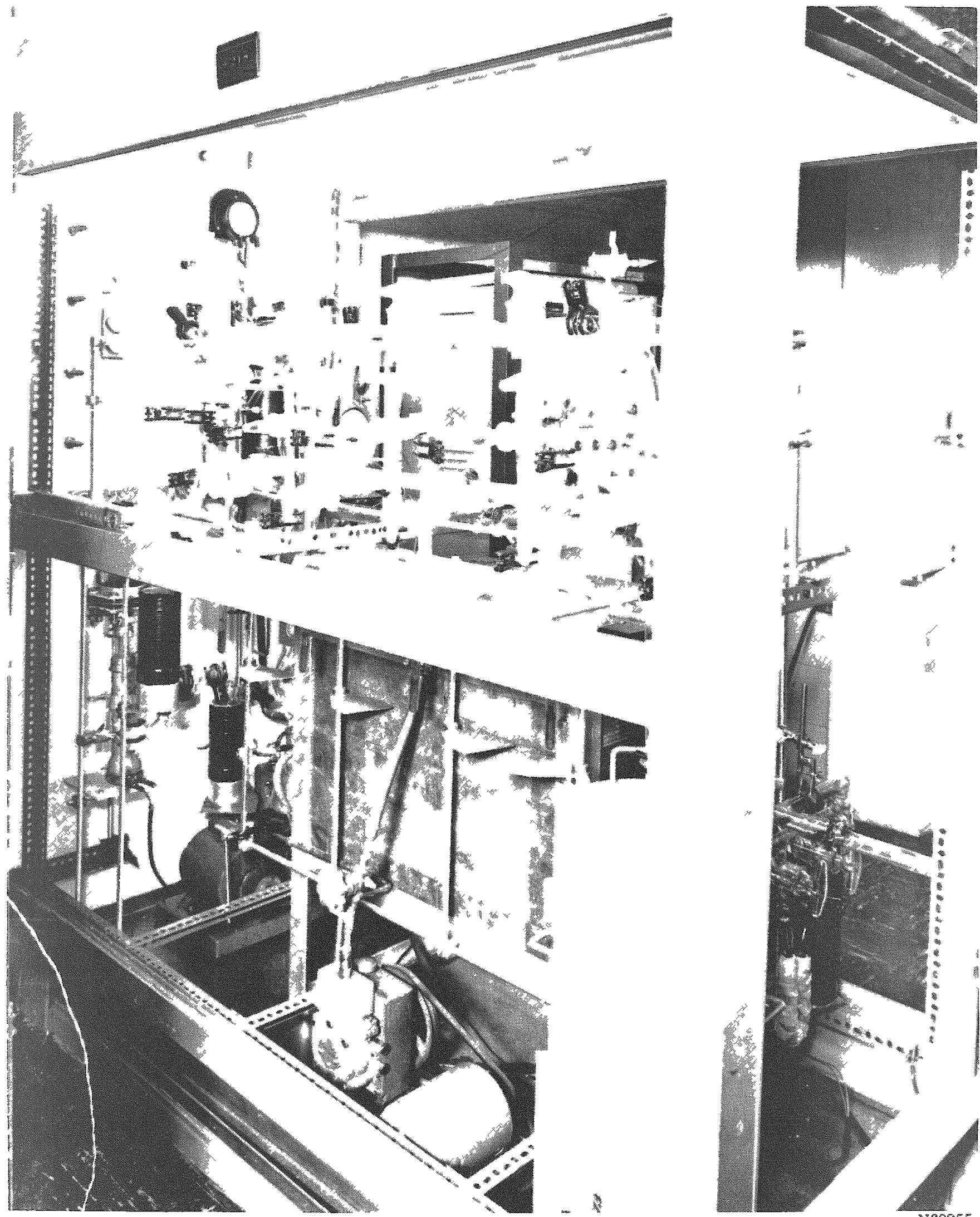

w

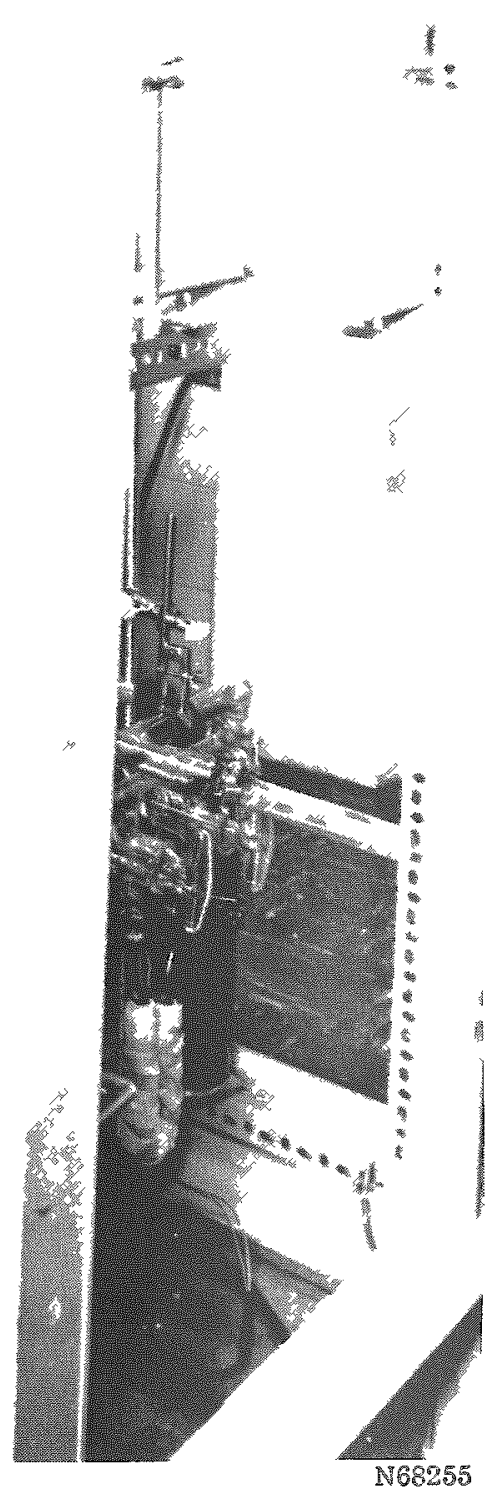

FIGURE 2. VEWW OF APPARATUS FOR POSTIRRADIATION FISSION-GAS-RELEASE STUDIES SHOWING GAS -COLLECTION MANIFOLD 


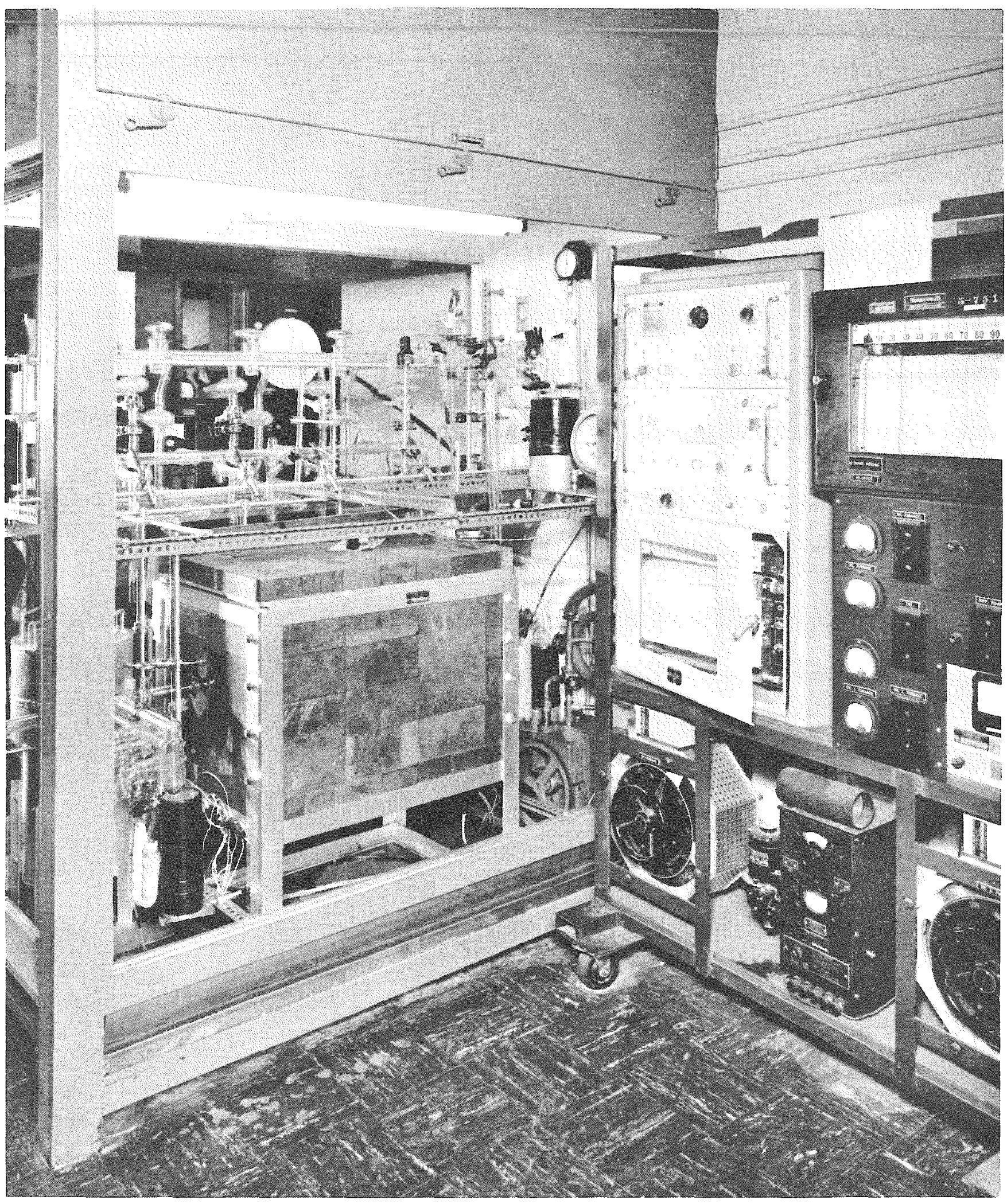

N68254

FIGURS 3. VIEW OF APPARATUS FOR POSTIRRADI TION FISSION-GAS-RELEASE STUDIES SHOWING THE FURNACE HOUSING AND RADIOASSAY AND TEMPERATURECONTROL DOLLY 
Details of the heat-treatment furnace are illustrated in Figure 4. Uniform temperatures in excess of $1600 \mathrm{C}$ can be produced over a length of 3 in. in the central portion of this furnace. The specimen is contained in either a Mullite or Zirco 1-in. - ID vacuumtight ceramic tube that passes through the furnace. The Mullite and Zirco tubes were procured from the McDaniel Company, Beaverfalls, Pennsylvania. Both ends of the ceramic tube are sealed to glass tubes and connected to the system with standard ball-and-socket joints. A platinum-platinum $30 \mathrm{w} / 0$ rhodium thermocouple is positioned inside the ceramic tube to measure the specimen temperature. This thermocouple is connected to a Foxboro potentiometer-type controller which controls the temperature by regulating the electrical power to the rhodium winding while the Chromel $\mathrm{A}$ winding idles. It is estimated that specimen temperatures are controlled to closer than $\pm 10 \mathrm{C}$.

Within the system, the specimen is held in the holder shown at the top of Figure 1. The holder consists of a tantalum tube which is connected by a piece of tantalum wire to a soft-iron rod enclosed in a glass tube. A magnet is used to move the holder with the specimen into the furnace tube until it contacts the control the rmocouple, which acts as a stop. By this means a specimen can be inserted or completely removed from the furnace in less than $5 \mathrm{sec}$ without disturbing the system.

The furnace section is completely enclosed by $2 \mathrm{in.}$ of lead shielding to reduce the radiation from the specimen. The enclosure is made of lead bricks held together by a steel frame.

Located downstream with respect to the furnace is a cold trap, which is cooled. with dry ice and acetone, and a silver trap. The traps retain the condensable nongaseous and the halogen fission products, preventing contamination of the continuous monilor and charcoal traps. The silver trap, which consists of a glass U-tube filled with silver shot, is operated at $300 \mathrm{C}$.

Figure 5 shows the arrangement of the continuous gas monitor. This monitor consists of a glass chamber with a well in which a 2 by 2 -in. scintillation crystal is located. The dimensions of the gas-monitoring chamber are shown in Figure 6. To minimize radiation background the monitor is provided with 2 in. of lead shielding. The output from the photomultiplier connected to the scintillation detector is fed to a recording singlechannel gamma-ray spectrometer. The base level and window width of the spectrometer axe adjusted to measure only those gamma rays of a particular energy that emanate from the fission-gas isotope of interest. When appreciable quantities of gamma rays of more than one energy are present, this technique is applied only to the highest energy photopeak. The Compton scattering associated with the highest energy photopeak makes quantitative interpretation of a lower energy peak difficult. The volume of the glass monitoring chamber is $885 \mathrm{ml}$. Detection efficiency for the monitoring system varies with gamma-ray energy. In the case of the $81-k e v$ gamma ray from xenon-133, the detection efficiency is about 4 per cent.

The manifold to which four charcoal traps are connected begins at the continuous monitoring chamber. The carrier-gas flow can be diverted through one trap, or any parallel combination of the four traps. Each trap accommodates about $6 \mathrm{~cm}^{3}$ of activated charcoal, as shown in Figure 7. For high-efficiency removal of fission gas from the helium carrier stream, the charcoal-containing portions of the traps are maintained at liquid-nitrogen temperature. The retention time of the traps depends on the type of charcoal that is used and the flow rate of carrier gas through the trap. With the 12 to 28-mesh Columbia HCC charcoal that is being used, the retention time is about $90 \mathrm{~min}$ for a flow rate of 5 liters per hr. During operation the traps can be readily disconnected 


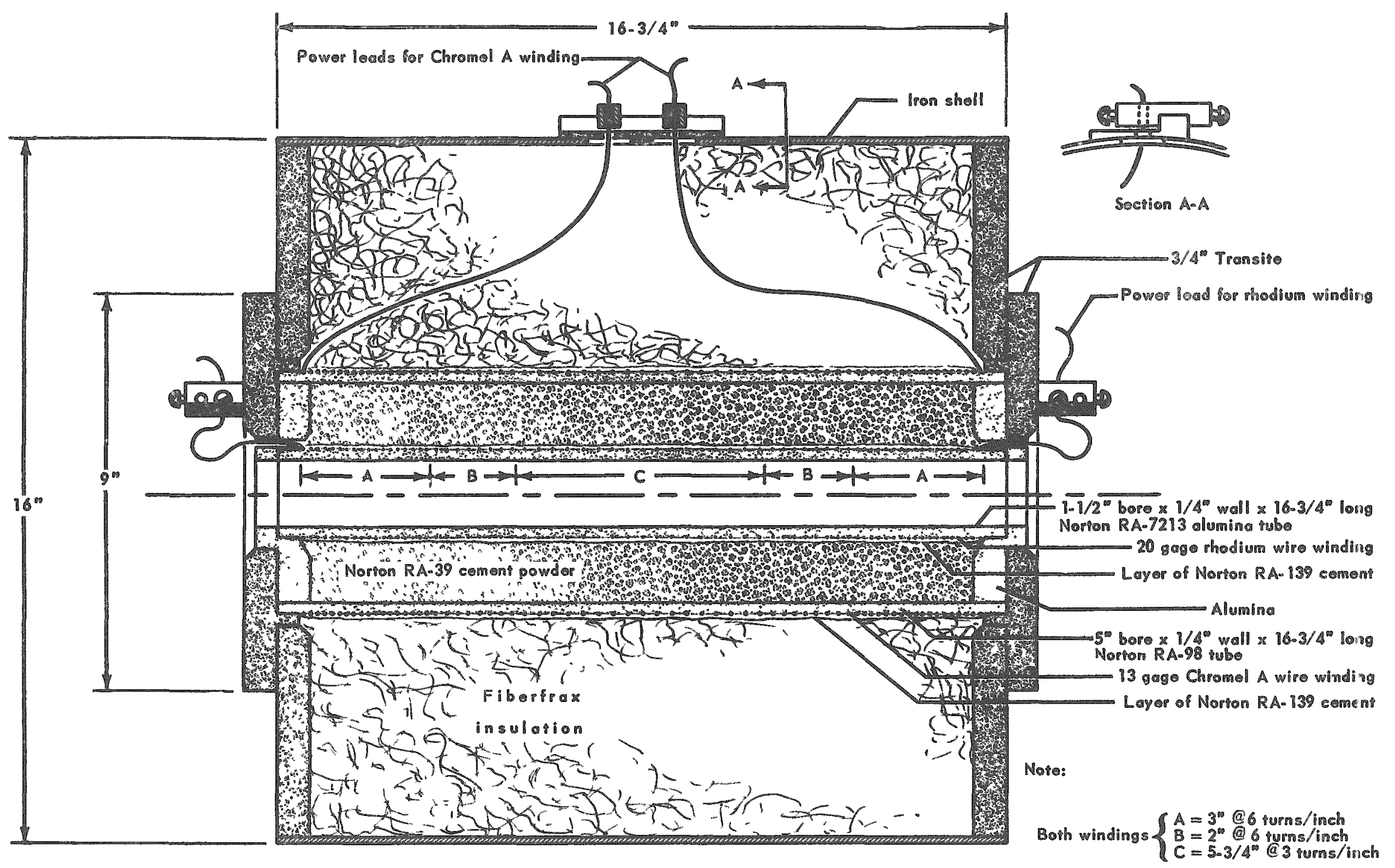

FIGURE 4. CROSS SECTION OF RHODIUM WOUND RESISTANCE FURNACE 


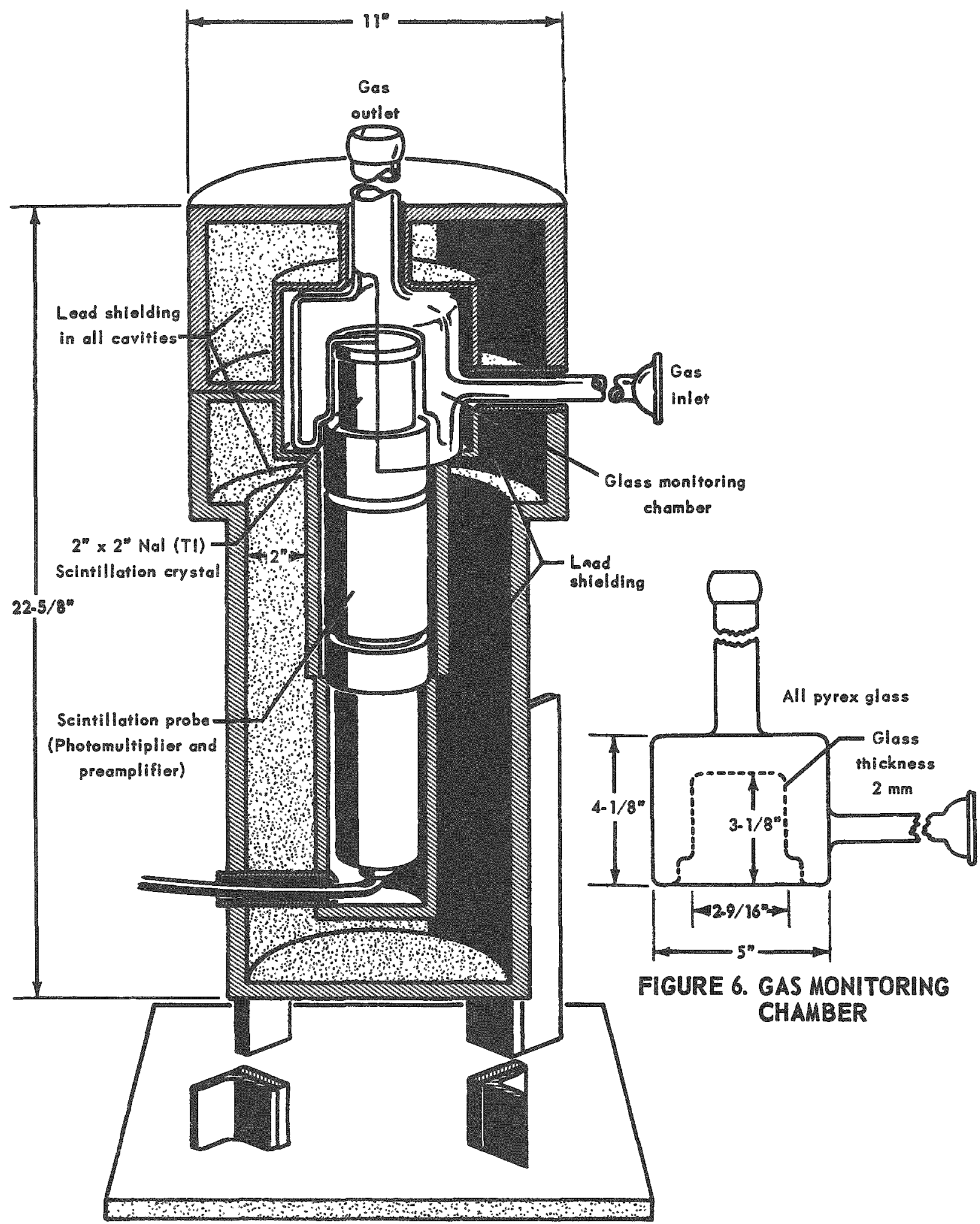

FICURE 5. CONTINUOUS RADIOACTIVITY MONITOR 


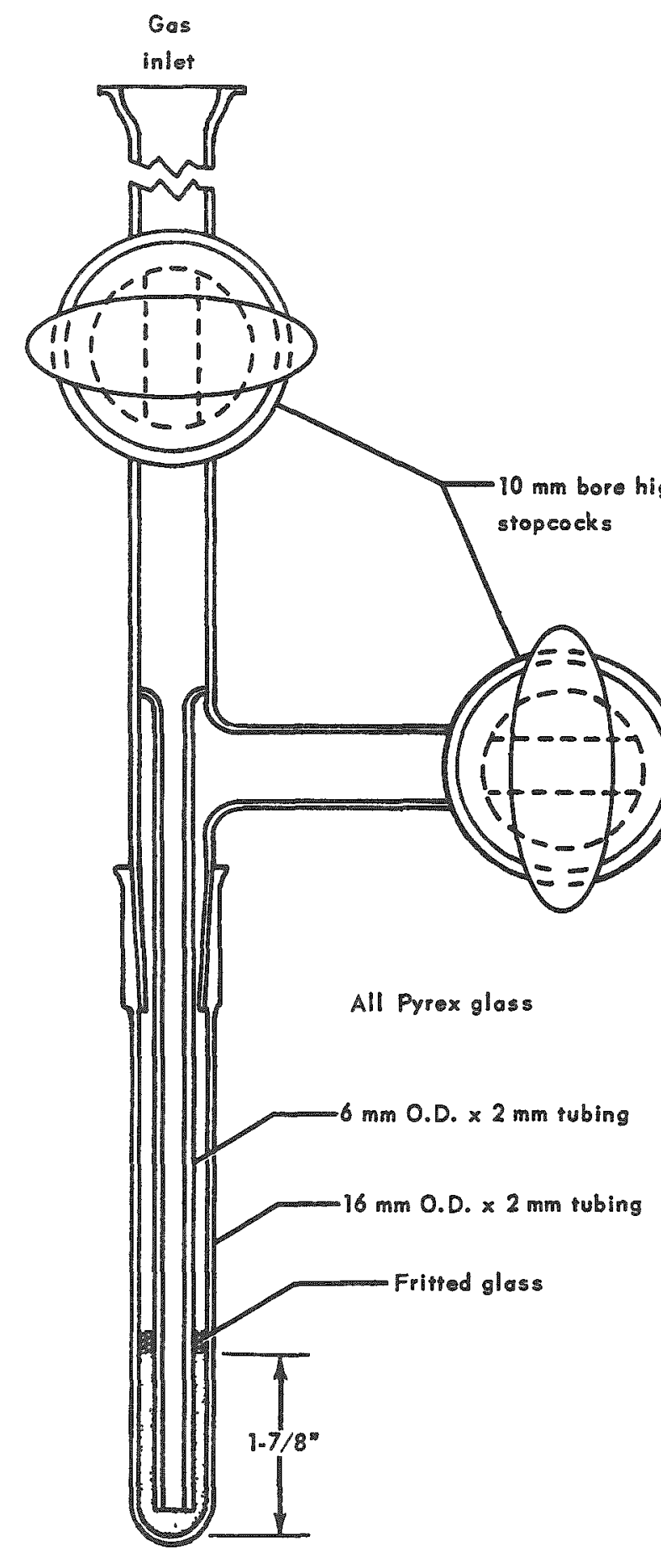

FIGURE 7. CHARCOAL FISSION-GAS COLLECTION TRAP 
from the system, the charcoal degassed by heating it under vacuum, and the trap replaced, without disturbing any other part of the system. A temperature of about $400 \mathrm{C}$ is used to degas the traps. The vacuum manifold for degassing the traps is equipped with a thermocouple-type vacuum gage which is used to determine when the carcoal is degassed and the trap is ready for use. About $10 \mathrm{~min}$ is usually necessary to degas a trap.

The radionuclides collected on the charcoal are analyzed by removing the trap from the system and inserting it into a gamma-scintillation well crystal for radioassay using a. gamma-ray spectrometer.

An additional charcoal trap is provided on the downstream side of the trap manifold. This trap is checked periodically during an experiment to assure that all the fission gas is retained on the analytical traps.

Pressure is measured at various points in the system with Bourdon-type pressurevacuum gages and a combination thermocouple-ionization gage. A McLeod gage is also incorporated in the system to calibrate the combination thermocouple-ionization gage.

Flow rate is determined by two methods. Rotameters are used to measure instantaneous flow rate. The cumulative volume of gas flow through the system is measured with a wet-test meter that is connected to the exhaust of the mechanical vacuum pump.

\section{OPERATING PROCEDURE}

The irradiated specimen is first placed in the specimen holder and introduced into the system. Prior to inserting the specimen into the furnace, the system is evacuated to minimize air and water vapor, and the desired pressure and carrier-gas flow rate are set. A magnet is then used to insert the specimen into the furnace which has already been brought to temperature. About $30 \mathrm{sec}$ is required for the specimen to reach the temperature of the furnace.

During an experiment, furnace temperature, helium flow rate and pressure, oxygen and moisture concentrations, and the activity measured by the continuous monitor are recorded. At the beginning of a heating period, when the fission-gas-release rate changes relatively rapidly with time, the charcoal adsoxption traps are changed on a 1/2hr schedule. Traps are then changed on a hourly basis after the release rate levels off. The traps are radioassayed immediately after they are removed from the system.

To illustrate the type of information that is recorded during an experiment, the data from a typical experiment are presented in Figure 8 and Table 1. This particular experiment involved the measurement of xenon-133 release from a small specimen of single-crystal uranium dioxide during heating at $1188 \mathrm{C}$. The specimen, which weighed about $1.24 \mathrm{~g}$, was irradiated for $640 \mathrm{~min}$ in a thermal-neutron flux of $6.6 \times 1012 \mathrm{nv}$ and then permitted to cool for about 5 days before heating. 


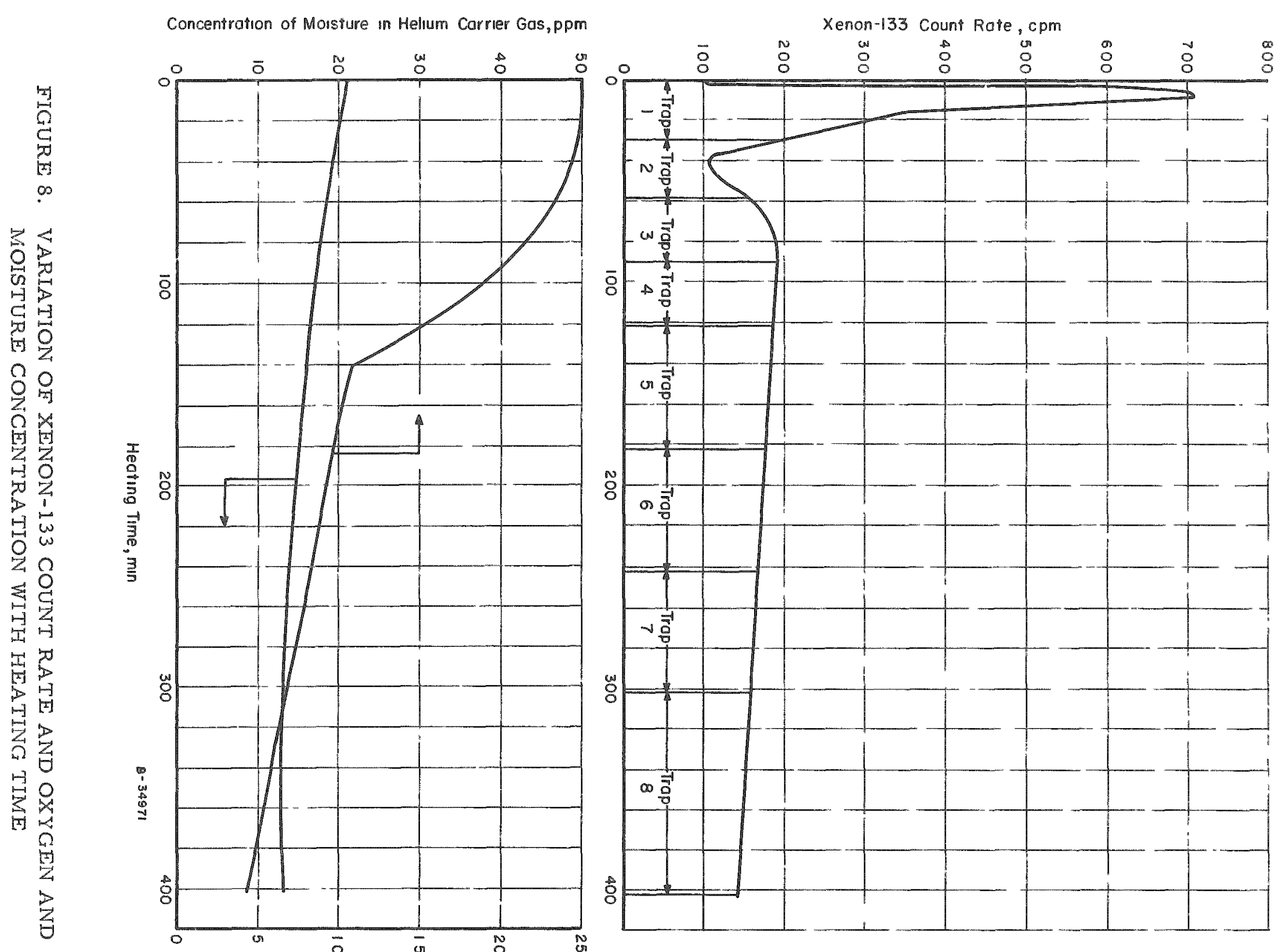


TABLE 1. RADIOASSAY OF CHARCOAL ADSORPTION TRAPS FOR XENON-133

\begin{tabular}{ccc}
\hline \hline & $\begin{array}{c}\text { Average Flow } \\
\text { Rate of Carrier } \\
\text { Gas, cm }{ }^{3} \text { permin }\end{array}$ & $\begin{array}{c}\text { Atoms of Xenon-133 } \\
\text { Collected in Charcoal } \\
\text { Adsorption Traps }\end{array}$ \\
\hline Trap & 46 & $2.26 \times 10^{8}$ \\
1 & 112 & $0.18 \times 10^{8}$ \\
2 & 26 & $0.36 \times 10^{8}$ \\
3 & 50 & $0.71 \times 10^{8}$ \\
4 & 59 & $1.25 \times 10^{8}$ \\
5 & 39 & $1.14 \times 10^{8}$ \\
6 & 57 & $1.01 \times 10^{8}$ \\
7 & 40 & $1.39 \times 10^{8}$ \\
8 & 40 & \\
\hline
\end{tabular}

Figure 8 shows the variation of the xenon-133 activity with time recorded during heating by the continuous monitoring system. Background radiation accounts for $100 \mathrm{cpm}$. The time intervals when the various fractions of the fission gas evolved from the specimen were collected on charcoal adsorption traps are designated. Results of the radioassays of the charcoal adsorption traps for xenon-133 are given in Table 1. The radioassays were performed on each fraction within a few minutes after collection of the gas. Concentrations of oxygen and moisture in the helium carrier gas are also presented in Figure 8. The curves in Figure 8 are smoothed representations of data from recorder charts.

Analysis of the data is directed toward developing an understanding of the mechanism of fission-gas release. The characteristics of the release rate-time relationship which is derived from the continuous-monitoring data offer insight into the release mechanism. Once a model has been developed the release-rate data can be interpreted in terms of diffusion coefficients and other properties of the material. The techniques which have been developed for the analysis and interpretation of the data will be presented in future reports.

\section{ACKNOW LEDGMENTS}

The authors wish to acknowledge the contributions made by Frank A. Rough, John J. Fancelli, O. Paul Walters, Peter Gluck, and Richard K. Patterson, all of the BMI staff, in the design and construction of the apparatus.

\section{REFERENCE}

(1) Rosenberg, H. S., Lieberman, R., Sunderman, D. N., and Diethorn, W. S., "Apparatus for the Study of Fission-Gas Release From Neutron-Activated Fueled Graphite", BMI-1444 (June 7, 1960). 